\title{
Currículo da Licenciatura em Computação: uma Proposta Alinhada às Novas Diretrizes e Demandas Contemporâneas
}

\author{
Taciana Pontual Falcão ${ }^{\text {ta }}$, Danilo R. B. de Araújo ${ }^{\text {ta }}$, Rozelma França ${ }^{2 a}$, Ermeson C. \\ de Andrade ${ }^{\text {ta }}$, César França ${ }^{\text {aa }}$
}

'Departamento de Computação e 'Departamento de Educação, Universidade Federal Rural de Pernambuco - UFRPE, Recife-PE, Brasil

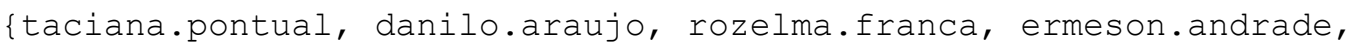

\begin{abstract}
The goal of this paper is to share with the national community of undergraduate courses for teachers the main ideas of a pedagogical project which meets the new Brazilian guidelines for these courses, and also meets the demands of citizenship in the contemporary society. We hope, with this project, to improve course completion indices, but also to strengthen the identity of computing teachers, valuing their role in the development of computational thinking and technical abilities since elementary education, as well as in the design and production of educational technologies.
\end{abstract}

Resumo. O objetivo desse artigo é compartilhar com a comunidade da Licenciatura em Computação as principais ideias de um projeto pedagógico de curso que atende às novas diretrizes nacionais para os cursos de licenciatura, ao mesmo tempo em que alinha o currículo ao contexto da sociedade contemporânea e as novas demandas de formação cidadã. Esperase com esse projeto melhorar os índices de sucesso no curso, mas também fortalecer a identidade do licenciado em Computação, valorizando seu papel no desenvolvimento do pensamento computacional e habilidades técnicas desde a educação básica, assim como na concepção e produção de tecnologias educacionais.

\section{Introdução}

O curso de Licenciatura em Computação (LC) da Universidade Federal Rural de Pernambuco - UFRPE foi instituído em 1999, pioneiro nas regiões Norte/Nordeste. Em 2002, a Licenciatura em Computação passou a integrar as Diretrizes Curriculares Nacionais (DCN) dos cursos de graduação em Computação da Sociedade Brasileira de Computação (SBC) com a criação do Currículo de Referência [SBC 2002]. O Censo da Educação Superior [INEP 2014] indica que ao longo da primeira década do milênio, a quantidade de cursos de LC no Brasil aumentou e diminuiu a depender do ano. O último relatório da SBC contabilizou 89 cursos de LC no Brasil no ano de 2016 [SBC 2016].

Em 2015, o Ministério da Educação instituiu as Diretrizes Curriculares Nacionais (DCNs) para a formação inicial em nível superior (cursos de licenciatura, cursos de formação pedagógica para graduados e cursos de segunda licenciatura) e para a formação continuada [CNE/CP 2015]. Em 2016, foram homologadas pelo Ministério da Educação as novas DCNs para os cursos de graduação em Computação, que tinham sido aprovadas pelo Conselho Nacional de Educação em 2012 [CNE/CES 2016]. Em 2017, a SBC lançou os Referenciais de Formação para os Cursos de Graduação em Computação [SBC 2017]. Esses conjuntos de diretrizes suscitaram demandas de

\footnotetext{
a Professores e membros do Núcleo Docente Estruturante do curso de Licenciatura em Computação da UFRPE.
} 
VII Congresso Brasileiro de Informática na Educação (CBIE 2018)

Anais dos Workshops do VII Congresso Brasileiro de Informática na Educação (WCBIE 2018)

adequação para todos os cursos de LC, seja por necessidade de cumprimento da nova legislação, seja para melhor alinhamento de currículo às recomendações da SBC. Na UFRPE, essas demandas somaram-se às necessidades de: estabelecer estratégias para combater as altas taxas de retenção e evasão do curso; suprir a ausência de conteúdos importantes de Computação no currículo obrigatório; repensar e adequar a implementação da carga horária da prática como componente curricular. Assim, em um primeiro momento foi realizado um planejamento estratégico pelos membros do Núcleo Docente Estruturante (NDE) do curso, definindo-se missão, visão, objetivos e metas. Esse planejamento trouxe à discussão as novas demandas contemporâneas de formação cidadã incluindo competências relacionadas a Computação e cultural digital, destacando o papel estratégico dos licenciados em Computação nesse cenário e assim fortalecendo o curso no departamento, onde havia questionamentos sobre a sua relevância.

Seguiu-se ao planejamento estratégico a elaboração do Projeto Pedagógico do Curso (PPC), aprovado pelo Conselho de Ensino, Pesquisa e Extensão da UFRPE em agosto de 2018. O objetivo deste artigo é compartilhar com a comunidade nacional das licenciaturas em Computação as principais propostas do PPC em consonância com as recomendações e resoluções mais recentes e as demandas sociais contemporâneas, visto que atender a tal diversidade de critérios é um processo complexo acompanhado de desafios importantes, incluindo nova carga horária total mínima, conteúdos humanísticos e sociais, gestão escolar, entre outras questões. Em especial, destacam-se neste artigo: uma proposta inovadora para os estágios curriculares; a reformulação das disciplinas de práticas de ensino; a introdução da modalidade a distância (dentro dos $20 \%$ da carga horária permitidos por lei); e a introdução do Trabalho de Conclusão de Curso em um formato flexível.

\section{Justificativa}

Uma pesquisa realizada no curso de LC da UFRPE por Vasconcelos e Andrade (2018) confirmou a grande retenção das disciplinas de Matemática Discreta e Introdução a Programação, ambas então no primeiro período do curso. Foi identificado também na pesquisa que $50 \%$ dos alunos entrevistados do primeiro período já tinham pensado em desistir do curso, assim como $73.1 \%$ dos alunos entrevistados do segundo período em diante. Dos nove professores entrevistados, cinco destacaram espontaneamente a necessidade de mudanças na matriz curricular então vigente. Vasconcelos e Andrade (2018) destacam a urgência de se trabalhar o currículo para melhorar a motivação e persistência dos alunos do curso. Entre as soluções propostas, os autores sugerem o desmembramento das disciplinas de Matemática Discreta e Introdução a Programação, dado o extenso e complexo conteúdo programático de ambas [Vasconcelos \& Andrade 2018]. Os autores mencionam ainda a reformulação das disciplinas de Prática de Ensino (em particular por serem lecionadas como co-requisitos das disciplinas técnicas, por exemplo: Redes e Prática de Ensino de Redes).

Além das questões mais pontuais citadas acima, o NDE percebeu também uma necessidade de introduzir inovações no currículo da LC sintonizadas com as novas diretrizes indicadas pelas sociedades científicas de Computação e as novas tendências mundiais na área de Educação em Computação. Nesse âmbito, o chamado "pensamento computacional" vem crescendo em importância como uma habilidade tão fundamental na sociedade contemporânea quanto ler, escrever e fazer cálculos. Com a quantidade de informação hoje a fácil alcance, os jovens estão sendo cobrados a irem muito além da memorização e repetição de conhecimento. O termo pensamento computacional (computational thinking), popularizado por Jeannette Wing em 2006 [Wing 2006], refere-se à capacidade de resolver problemas usando raciocínio lógico e algorítmico, e técnicas como decomposição, abstração e recursão, entre outras. Buscando atender tais demandas países como Estados Unidos, Inglaterra e Austrália têm sido pioneiros em introduzir o pensamento computacional nos currículos das escolas [Wing 2016; BCS 2016; CSTA/ISTE 2011]. No Brasil, pesquisas na área têm se multiplicado rapidamente 
VII Congresso Brasileiro de Informática na Educação (CBIE 2018)

Anais dos Workshops do VII Congresso Brasileiro de Informática na Educação (WCBIE 2018)

(vide anais mais recentes do Congresso Brasileiro de Informática na Educação - $\mathrm{CBIE}^{2}$, em particular o Workshop de Ensino em Pensamento Computacional, Algoritmos e Programação - WAlgProgs; e o Workshop de Educação em Computação do Congresso da Sociedade Brasileira de Computação - WEI/CSBC ${ }^{4}$ ). Além disso, o Centro de Inovação para a Educação Brasileira (CIEB) construiu um currículo de referência em Tecnologia e Computação para o Ensino Fundamental, com três grandes eixos: Cultura Digital; Tecnologia Digital e Pensamento Computacional - com versão integral a ser lançada em outubro de 2018. O currículo articula-se com a Base Nacional Curricular Comum (BNCC) proposta pelo Ministério da Educação. Graças à atuação da comunidade brasileira de Informática na Educação, a BNCC teve a sua Competência Geral 5 reformulada para contemplar a criação e produção de tecnologias e conhecimentos, ligados à resolução de problemas - indo além da utilização de recursos tecnológicos.

Diante desse panorama, os cursos de Licenciatura em Computação crescem enormemente em importância, ganhando papel de destaque e necessitando adequar seus projetos pedagógicos para garantir a formação de profissionais com a competência de promover o desenvolvimento do pensamento computacional, proporcionar e mediar o uso e criação de tecnologias digitais, como docentes na educação básica, contribuindo para que as escolas atendam às demandas contemporâneas para a formação de cidadãos.

Por fim, outra linha em expansão relaciona-se ao empreendedorismo e inovação na educação. Um recente mapeamento [CIEB 2018] mostra que existem no Brasil 364 startups que trabalham com tecnologias educacionais, sendo $47 \%$ no segmento da educação básica. Assim, é importante despertar a cultura empreendedora dos licenciandos, estimulando principalmente o projeto e desenvolvimento de tecnologias educacionais inovadoras, e a inovação na educação quebrando paradigmas pedagógicos (primordialmente baseados em exposição de conteúdos) e/ou de gestão, introduzindo novas formas de construir conhecimento apoiadas por usos criativos das tecnologias.

\section{A Nova Identidade do Curso}

\subsection{Objetivos}

De acordo com as DCNs [CNE/CES 2016], os cursos de LC têm como objetivo principal "preparar professores para formar cidadãos com competências e habilidades necessárias para conviver e prosperar em um mundo cada vez mais tecnológico e global e que contribuam para promover o desenvolvimento econômico e social de nosso país". Os objetivos do curso de LC da UFRPE, delineados em seu novo PPC, foram pensados em consonância com tal orientação e com os aspectos apresentados na seção anterior. Assim, o objetivo geral é: formar profissionais com sólida base humanística e tecnológica para atuar como professores na educação básica e em espaços não escolares, e na pesquisa, desenvolvimento e inovação em práticas educacionais. E os objetivos específicos são:

- Formar profissionais cientes da importância da introdução e desenvolvimento do pensamento computacional e algorítmico na educação básica, e protagonistas de iniciativas nesse sentido, em contextos interdisciplinares;

- Fomentar e desenvolver práticas criativas e inovadoras de ensino com o apoio de tecnologias contemporâneas, que sejam tanto aplicadas no curso quanto aprendidas pelos discentes para seu futuro como educadores;

hhttp://br-ie.org/pub/index.php/sbie/index; http://www.br-ie.org/pub/index.php/wie

3http://www.br-ie.org/pub/index.php/wcbie/index

http://ebooks.pucrs.br/edipucrs/anais/csbc/\#/home; http://www.lbd.dcc.ufmg.br/colecoes/wei/

${ }^{s} \mathrm{http} / / /$ curriculo.cieb.net.br/ 
VII Congresso Brasileiro de Informática na Educação (CBIE 2018)

Anais dos Workshops do VII Congresso Brasileiro de Informática na Educação (WCBIE 2018)

- Formar profissionais para atuar no projeto, desenvolvimento, avaliação e gestão de tecnologias em contextos educacionais;

- Desenvolver valores humanos orientados a compromisso social, sustentabilidade, diversidade e ética, que devem nortear a atuação do egresso, em especial no uso de tecnologias visando o bem social e comunitário.

\subsection{Perfil do Profissional e Campo de Atuação}

O profissional formado em LC deve ser um educador que, utilizando os avanços tecnológicos, seja capaz de gerar inovações nos processos de ensino e aprendizagem, sendo agente integrador entre os conteúdos da formação do estudante. Deve ser um profissional crítico, com formação pedagógica, computacional, ética e humanística, capaz de aplicar o conhecimento adquirido ao longo de sua formação de modo a propor soluções tecnológicas criativas e inovadoras para problemas relativos às suas diferentes áreas de atuação. Assim, os egressos do curso de LC serão dotados de um repertório de informações e habilidades composto pela pluralidade de conhecimentos teóricos e práticos das áreas de Educação e Computação, o que lhes permitirá atuar profissionalmente em instituições de educação (incluindo as séries finais do Ensino Fundamental, Ensino Médio, Educação Profissional Técnica de nível Médio, demais cursos técnicos e Organizações Não Governamentais), mas também em empresas de consultoria, assessoria e desenvolvimento de tecnologias educacionais.

A primeira vertente busca atender à demanda crescente das escolas que estão em processo de modernização tecnológica, por meio da inserção de recursos tecnológicos em diferentes dimensões de seus processos educacionais. Dentre essas dimensões encontram-se: a gestão dos recursos de informática de maneira integrada à gestão escolar e ao desenvolvimento dos conteúdos em sala de aula; e o desenvolvimento do pensamento computacional em oficinas, clubes, atividades complementares em escolas integrais, atividades optativas dos currículos ou de forma integrada às matérias obrigatórias, e dentro de um contexto de cultura digital. O desenvolvimento do pensamento computacional pode ser feito por meio de diversas abordagens que trabalham raciocínio lógico e algorítmico para resolução de problemas, entre as quais a mais comum é o ensino de programação. Clubes de programação em escolas já existem como atividades optativas e têm tido sua importância cada vez mais reconhecida.

Já a segunda vertente visa suprir a demanda por artefatos tecnológicos educacionais de qualidade. $\mathrm{O}$ papel do licenciado em Computação é crucial como um profissional que compreende os requisitos técnicos de desenvolvimento mas também as questões pedagógicas fundamentais para a eficácia dos produtos gerados, podendo atuar tanto no desenvolvimento, quanto no projeto e avaliação das tecnologias.

Uma outra importante área de atuação para os licenciados em Computação é a Educação a Distância (EAD), um campo que vem crescendo no Brasil, possibilitando uma maior democratização da educação. Os ambientes virtuais de aprendizagem (AVA) são cada vez mais usados em cursos a distância e como apoio ao ensino presencial, e fazem-se necessários profissionais capacitados para atuar em gestão de EAD; configuração dos AVAs; produção de materiais didáticos para esse contexto; além da própria metodologia de ensino para contextos não presenciais.

\subsection{Competências, Atitudes e Habilidades}

O novo PPC do curso de LC da UFRPE propõe uma formação direcionada para: Desenvolver atividades de docência e pesquisa em Computação e Educação; Conduzir investigações e contribuir para o desenvolvimento do conhecimento na área de Computação e Educação de maneira interdisciplinar; Analisar criticamente a realidade escolar, intervindo de maneira ética e humanística; Atuar no planejamento e execução de currículos e programas de capacitação profissional em organizações diversas, e em 
VII Congresso Brasileiro de Informática na Educação (CBIE 2018)

Anais dos Workshops do VII Congresso Brasileiro de Informática na Educação (WCBIE 2018)

especial aquelas relacionadas a métodos, processos e técnicas da Computação; Projetar, implementar, avaliar e gerir ferramentas e soluções computacionais de apoio aos processos de ensino e aprendizagem e gestão escolar para atender às demandas das escolas e instituições de ensino, inclusive contemplando as diversas formas de acessibilidade; Participar da elaboração, execução e gestão de projetos na área de educação a distância ou atividades educativas com a mediação de tecnologias de informação e comunicação; Desenvolver recursos didáticos (softwares educacionais em geral, ambientes virtuais de aprendizagem, jogos educacionais, etc.); Contribuir para a geração de inovações nos processos de ensino e aprendizagem de maneira a atender às demandas de formação de educadores comprometidos com a transformação social e tecnológica.

\section{Organização Curricular}

A formação do licenciado em Computação demanda uma visão sistêmica capaz de integrar as especificidades das áreas de Educação e Computação. Para tanto, o currículo proposto é norteado pelos documentos da SBC que apresentam DCNs para cursos de graduação em Computação [CNE/CES 2016] e Referenciais de Formação para os Cursos de Graduação em Computação [SBC 2017]; e pelas DCNs para formação superior em cursos de licenciatura [CNE/CP 2015]. Consideram-se as áreas de formação propostas pela SBC e leva-se em conta também o agrupamento de componentes curriculares sugeridos pelas diretrizes da SBC para cursos de LC. São consideradas 3 áreas de formação para o planejamento dos componentes curriculares, a saber: formação básica; formação tecnológica; e formação humanística e complementar.

A formação básica contempla os fundamentos das áreas de: Ciência da Computação (técnicas básicas da Computação, do raciocínio lógico e de resolução de problemas, da organização e manipulação de informações armazenadas; da organização e arquitetura de computadores); Matemática (capacidade de abstração, modelagem, manipulação e resolução simbólica de problemas por meio de raciocínio lógico); e Áreas Pedagógicas (princípios que norteiam a ação pedagógica; formas de aprendizagens; compreensão da escola no contexto do sistema de educação brasileiro; e as tecnologias, métodos e estratégias de ensino).

A formação tecnológica contempla conteúdos de tecnologias básicas de suporte (como sistemas operacionais, redes de computadores e banco de dados, por exemplo); tecnologias de modelagem, especificação e desenvolvimento de sistemas (como engenharia de software e interface humano-computador, por exemplo); gestão de tecnologias educacionais; e prática de ensino de computação.

A formação humanística e complementar está relacionada às necessidades da prática do educador e à forte ligação da LC com a inovação dos processos educacionais, requerendo a compreensão e análise crítica do contexto social, educacional, econômico, cultural e político, visando o desenvolvimento e o empreendedorismo em ciência e tecnologia, integrado às questões sociais. Assim, a formação humanística e social deve contemplar, de forma transversal ou disciplinar, princípios éticos e direitos humanos, aspectos étnico-raciais, diversidade de gênero, sexual, religiosa e de faixa geracional, educação ambiental e educação para diversidade e inclusão.

Em relação à matriz anterior, foram incluídas novas disciplinas que se tornaram obrigatórias para todas as licenciaturas, a saber: Produção de Textos Acadêmicos; Libras; Educação das Relações Étnicorraciais; e Metodologia do Ensino. Foram também incluídas como obrigatórias disciplinas técnicas que antes eram apenas componentes optativos, mas que foram considerados de extrema importância para uma sólida formação em Computação: Engenharia de Software, Circuitos Digitais e Inteligência Artificial, além da atualização das disciplinas de Arquitetura e Organização de Computadores e Sistemas Operacionais. Em relação às disciplinas consideradas "híbridas" de Computação e Educação, foram tornadas obrigatórias as disciplinas de 
VII Congresso Brasileiro de Informática na Educação (CBIE 2018)

Anais dos Workshops do VII Congresso Brasileiro de Informática na Educação (WCBIE 2018)

Tecnologias na Educação e Educação a Distância; e foram criadas as disciplinas (obrigatórias) de Introdução a Ambientes Virtuais de Aprendizagem, Pensamento Computacional e Projeto de Software Educacional, além de diversas optativas como Robótica Educacional, Mineração de dados educacionais, e Jogos na Educação.

Além dessa modernização, a nova matriz busca também de forma específica amenizar os problemas de retenção diagnosticados no início do curso. Para tanto, a disciplina de Matemática Discreta foi desmembrada em duas (primeiro e segundo período); e a disciplina de Introdução a Programação foi desmembrada em Programação I e Laboratório de Programação I (ambas colocadas no segundo período). Assim, em vez de cursar no primeiro período uma disciplina de 90 horas/aula em que precisavam aprender os fundamentos /lógica de programação e também uma linguagem de programação imperativa, os alunos agora cursam no segundo período uma disciplina de 60 horas/aula de Programação, em que aprendem uma linguagem imperativa, combinada a uma disciplina de 30 horas/aula, ministrada na modalidade a distância, focada na prática de programação (Laboratório de Programação). O mesmo é seguido no terceiro período, com a programação orientada a objeto. Já no primeiro período, foi introduzida a disciplina de Pensamento Computacional, trabalhando os fundamentos do raciocínio algorítmico, decomposição de problemas, abstração, entre outros. Além de para preparar os alunos a aprender programação, essa disciplina possui metade de sua carga horária como prática como componente curricular, com discussões focadas em como desenvolver o pensamento computacional na educação básica, incluindo metodologias e ferramentas.

É importante também destacar o maior espaço dado à EAD na nova matriz, em duas frentes. Foi criada no primeiro período a disciplina de Introdução a Ambientes Virtuais de Aprendizagem, visto que muitos professores do curso usam o AVA como apoio às aulas presenciais, e vários alunos enfrentam dificuldades com o ambiente. Além disso, essa disciplina torna-se fundamental para que os alunos acompanhem bem as disciplinas da nova matriz ministradas a distância. $\mathrm{O}$ fato dos alunos terem uma maior imersão no AVA e vivenciarem a modalidade a distância também lhes dá a oportunidade de conhecer melhor uma área que é um importante campo de atuação profissional. Além disso, a disciplina de Educação a Distância passou a ser obrigatória, suprindo o conteúdo teórico e conceitual.

Por fim, foi também introduzido o Trabalho de Conclusão de Curso (TCC), antes ausente no currículo. O TCC deverá ser um trabalho individual e ter a forma de monografia, artigo científico, ou compilação de artigos científicos de autoria do discente. São exemplos de trabalhos esperados para o licenciado em Computação, seja para a modalidade de monografia ou artigo: relato de pesquisa; relato e documentação técnica sobre o desenvolvimento de tecnologia ou processo tecnológico; relato de uma revisão de literatura.

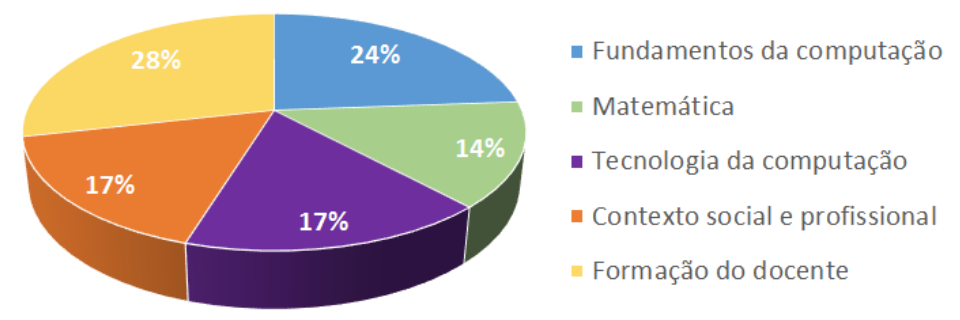

Figura 1. Percentual de componentes curriculares obrigatórios por subárea formativa

A Figura 1 mostra os componentes curriculares organizados em grupos de disciplinas, inspirados nas diretrizes curriculares da SBC [SBC 2002]: Fundamentos da 
VII Congresso Brasileiro de Informática na Educação (CBIE 2018)

Anais dos Workshops do VII Congresso Brasileiro de Informática na Educação (WCBIE 2018)

Computação; Matemática; Tecnologia da Computação; Contexto Social e Profissional; e Formação do Docente. São apresentados os percentuais de componentes obrigatórios em cada um dos 5 agrupamentos formativos, reforçando que a matriz curricular apresenta um equilíbrio adequado entre as diversas subáreas. O PPC em sua íntegra estará em breve disponível no site do curso ${ }^{6}$.

\subsection{Estágio Supervisionado Obrigatório}

Pelas exigências legais [CNE/CP 2015], o discente de LC deve cumprir no mínimo 400 horas de estágio supervisionado obrigatório (ESO), na área de formação e atuação na educação básica e outras áreas específicas. Na proposta aqui apresentada, o ESO é dividido em 4 componentes curriculares (Estágio I, II, III e IV), iniciando no $6^{\circ}$ período, ou seja, na segunda metade do curso. A carga horária total é de 405 horas, sendo120 horas de atividades teóricas e 285 horas de atividades práticas.

A proposta de conteúdo visa contemplar as duas principais esferas de atuação do profissional licenciado em Computação: a docência e o campo de projeto, desenvolvimento e avaliação de tecnologias educacionais. Dessa forma, o primeiro ano de estágio (Estágios I e II) deve ser obrigatoriamente realizado em instituições de ensino básico (fundamental, médio e/ou integrado médio-técnico), provendo a experiência prática necessária para a formação do docente apto a atuar em escolas. Essa experiência relaciona-se não somente a teorias relacionadas à aprendizagem, mas também ao principal diferencial do curso de LC, desenvolvido em disciplinas híbridas (que unem Computação e Educação), que é a integração das tecnologias e do pensamento computacional nos processos de aprendizagem, de forma transdisciplinar, nas instituições de ensino.

Nos dois semestres seguintes (Estágios III e IV), o estudante pode continuar na área de docência, com a possibilidade de ampliar sua atuação para outros tipos de instituições de ensino, em setores de capacitação de empresas ou órgãos públicos na área de Computação, expandindo as opções de atuação do educador para a esfera da capacitação profissional e formação continuada; ou especializar-se na área de TI, atuando em empresas do setor de tecnologias educacionais (desenvolvimento e avaliação de software e hardware). As propostas específicas de estágios III e IV em empresas e outras instituições que não sejam escolas deverão ser submetidas ao Colegiado de Coordenação Didática do curso, para avaliação e alinhamento do plano de trabalho do estudante ao campo de tecnologias de informação. No contexto das empresas de tecnologias educacionais, as atividades desenvolvidas pelo licenciando em seu estágio devem ser fundamentadas nas disciplinas híbridas características dos cursos de LC, que por sua vez apoiam-se em teorias educacionais, metodologias formais de desenvolvimento de software e diretrizes de design de interação e interface, para orientar o projeto de produtos eficazes e relevantes para a educação. Tal proposta para os ESOs representa uma das melhorias significativas do atual PPC, visto que anteriormente todos os estágios curriculares eram obrigatoriamente realizados em escolas, limitando a atuação dos licenciandos e negando-lhes a rica e necessária imersão em ambientes de concepção de tecnologias educacionais.

\subsection{Prática como Componente Curricular}

Pelas exigências legais [CNE/CP 2015], os cursos de licenciatura devem incluir, além da vivência proporcionada pelos estágios, 400 horas de atividades práticas relacionadas à docência, classificadas como Prática como Componente Curricular (PCC). Segundo o Parecer $n^{\circ}$ 15/2005 [CNE/CES 2005],

a prática como componente curricular é o conjunto de atividades formativas que proporcionam experiências de aplicação de conhecimentos ou de desenvolvimento

\footnotetext{
${ }^{6}$ www.lc.ufrpe.br
} 
VII Congresso Brasileiro de Informática na Educação (CBIE 2018)

Anais dos Workshops do VII Congresso Brasileiro de Informática na Educação (WCBIE 2018)

de procedimentos próprios ao exercício da docência. Por meio destas atividades, são colocados em uso, no âmbito do ensino, os conhecimentos, as competências e as habilidades adquiridos nas diversas atividades formativas que compõem o currículo do curso. As atividades caracterizadas como prática como componente curricular podem ser desenvolvidas como núcleo ou como parte de disciplinas ou de outras atividades formativas.

O parecer alerta para a diferenciação entre a PCC e o ESO. No perfil curricular aqui proposto, a PCC é contemplada por meio de atividades em disciplinas que exercitam a prática do ensino dos conceitos básicos da área de Computação, usando métodos considerados na literatura como adequados para a construção desse tipo de conhecimento. Alguns componentes curriculares possuem carga horária integral de PCC, e outros possuem uma porcentagem da carga horária relativa a PCC. Essa nova abordagem para a PCC introduz melhorias significativas em relação à matriz anterior, em que a carga horária era distribuída por várias disciplinas específicas como: Prática de Ensino de Redes, Prática de Ensino de Interfaces Homem-Máquina, Prática de Ensino de Algoritmos, e assim por diante - previstas para o mesmo período da disciplina técnica correspondente. Por um lado, as disciplinas serem ministradas no mesmo semestre dificultava a PCC, visto que o estudante ainda estava apropriando-se dos conteúdos técnicos em questão. Por outro lado, as disciplinas de prática de ensino, todas de 60 horas-aula, eram muito extensas para um conteúdo relativamente restrito na maioria dos casos.

$\mathrm{Na}$ atual matriz, os componentes curriculares com maior carga horária de PCC são: Pensamento Computacional; Introdução a Ambientes Virtuais de Aprendizagem; Tecnologias na Educação; Educação a Distância; Projeto de Sistemas Educacionais; Prática de Ensino de Computação I (cuja ementa contempla metodologias para o ensino de computação focadas na construção de conhecimento; aprendizagem significativa, aprendizagem ativa e aprendizagem baseada em problemas; uso de tecnologias digitais adequadas nos processos de ensino de computação); Prática de Ensino de Computação II (cuja ementa contempla métodos e ferramentas para ensino de programação, incluindo ferramentas de programação visual e abordagens lúdicas); e Trabalho de Conclusão de Curso. Dá-se um especial destaque para o desenvolvimento de pensamento computacional e a prática do ensino de programação, dadas as dificuldades de aprendizagem conhecidas nessa área, que se constitui como um importante campo de pesquisa em Educação em Computação (vide anais do Workshop de Educação em Computação do CSBC). A PCC contempla também o uso de ferramentas tecnológicas de apoio ao ensino presencial e a distância, tais como ambientes virtuais de aprendizagem e sistemas de verificação automática de exercícios de programação, essenciais à atividade docente do licenciado em Computação.

\section{Discussão}

Os cursos de licenciatura enfrentam presentemente necessidades de mudanças causadas por um lado pela adequação à nova legislação de formação de professores, e por outro lado pela crescente valorização da inserção de conteúdos ligados ao pensamento computacional da educação básica, que vem estimulando novas ideias para a formação dos licenciados em Computação. Docentes, discentes e egressos de cursos de LC passam a ter uma função-chave no debate sobre como conteúdos de Computação e de pensamento computacional podem ser trabalhados no ensino fundamental e médio, e como podem ser incluídos na BNCC. Já existem uma forte mobilização de docentes ligados a cursos de LC no Brasil para influenciar e enriquecer esse debate, e uma proposta concreta de currículo de Tecnologia e Computação para a Educação Básica a ser lançada em breve conforme site do CIEB'.

\footnotetext{
${ }^{7}$ http://curriculo.cieb.net.br/
} 
VII Congresso Brasileiro de Informática na Educação (CBIE 2018)

Anais dos Workshops do VII Congresso Brasileiro de Informática na Educação (WCBIE 2018)

Neste contexto é importante ressaltar que atualmente a Computação ainda não integra, oficialmente, o currículo da educação básica brasileira, embora haja iniciativas relacionadas que tendem a se espalhar cada vez mais pelo país. Assim, de modo a propiciar a atuação dos licenciandos em Computação nas escolas por meio dos estágios curriculares e programas de iniciação à docência, diversas estratégias têm sido adotadas na LC da UFRPE, dentre as quais: i) observações de aulas em contextos formais e não formais de ensino; ii) auxílio ao uso de tecnologias na prática pedagógica de professores da educação básica; iii) desenvolvimento de tecnologias educacionais pelos licenciandos; iv) planejamento e regência de cursos envolvendo fundamentos da Computação, a estudantes e professores da educação básica.

Ao receber estagiários da LC, as instituições de ensino têm a oportunidade de ter contato com novas tendências relacionadas ao desenvolvimento do pensamento computacional no ensino básico, assim como práticas inovadoras de ensino e gestão apoiadas por tecnologias. A presença dos estagiários pode proporcionar uma rica troca de conhecimentos com a equipe docente. Entretanto, torna-se cada vez mais evidente a necessidade da criação do cargo de professor de Computação, que seria idealmente ocupado pelos licenciados em Computação, que já possuem uma formação com esse objetivo. Atualmente, $98 \%$ das escolas brasileiras declaram possuir algum processo de tecnologia, mas apenas 27\% declaram fazer uso claro das mesmas [CIEB 2018]. As razões mais citadas são a falta de treinamento e a falta de conhecimento de gestores e professores [CIEB 2018] - o que deixa clara a necessidade da inserção mais efetiva do licenciado em Computação nas escolas.

Nas empresas de tecnologias educacionais, a interação com um estagiário da LC tem o potencial de despertar os desenvolvedores (de perfil essencialmente técnico) para questões pedagógicas, assim como melhorar a compreensão técnica dos pedagogos. $\mathrm{O}$ perfil interdisciplinar do estudante da LC pode melhorar a comunicação das equipes e estabelecer um vocabulário comum. É importante também estimular $\mathrm{O}$ empreendedorismo e engajamento dos licenciados em Computação nos processos de concepção e desenvolvimento de tecnologias educacionais. Nesse sentido, a proposta aqui apresentada flexibiliza os estágios curriculares para permitir que os discentes experimentem, além do ambiente escolar, uma imersão em empresas que desenvolvem tecnologias educacionais, visto que seu conhecimento técnico e pedagógico é uma contribuição valiosa nesse campo. Disciplinas como Empreendedorismo, Tecnologias na Educação e Projeto de Software Educacional, entre outras, proveem uma formação substancial nesse campo.

Um outro campo com oportunidades diversas é a EAD. No novo PCC, seis componentes curriculares serão ministrados integralmente na modalidade a distância (respeitando o limite máximo de $20 \%$ da carga horária a distância, em cursos presenciais [CNE/CES 2006]), com encontros avaliativos nos sábados pela manhã. Por um lado, isso permite atender as cargas horárias mínimas exigidas por lei, ao mesmo tempo contemplando o conteúdo técnico desejado de Computação, e mantendo o tempo de curso em 4,5 anos. Por outro lado, é também uma oportunidade para os discentes vivenciarem o funcionamento dessa modalidade. A EAD hoje carece fortemente de profissionais em design instrucional, capazes de conceber e produzir sequências e materiais didáticos adequados a essa modalidade.

A partir da implantação dessa nova matriz, a coordenação do curso da LC da UFRPE, com o apoio do NDE, pretende monitorar as taxas de retenção e evasão, analisando as melhorias esperadas, assim como a taxa de sucesso na graduação. Pretende-se também acompanhar o interesse dos discentes pela docência em Computação - o que pode ser percebido pela participação em programas de iniciação a docência como PIBID e Residência Pedagógica, além do monitoramento da atuação profissional dos egressos, dado o aumento gradual de oportunidades de trabalho na área. 
VII Congresso Brasileiro de Informática na Educação (CBIE 2018)

Anais dos Workshops do VII Congresso Brasileiro de Informática na Educação (WCBIE 2018)

\section{Referências}

BCS (2016) Computing At School. BCS, The Chartered Institute for IT. Disponível em: http://www.computingatschool.org.uk/.

CIEB (2018) Mapeamento Edtech: Investigação sobre as tecnologias educacionais no Brasil. Centro de Inovação para a Educação Brasileira - CIEB.

CNE/CES (2005) Parecer $n^{\circ}$ 15/2005, de 2 de fevereiro de 2005. Solicitação de esclarecimento sobre as Resoluções CNE/CP $\mathrm{n}^{\circ} \mathrm{s} 1 / 2002$, que institui Diretrizes Curriculares Nacionais para a Formação de Professores da Educação Básica, em nível superior, curso de licenciatura, de graduação plena, e $2 / 2002$, que institui a duração e a carga horária dos cursos de licenciatura, de graduação plena, de Formação de Professores da Educação Básica, em nível superior. Conselho Nacional de Educação / Câmara de Educação Superior. Ministério da Educação.

CNE/CES (2006) Parecer $n^{\circ}$ 281/2006 Conselho Nacional de Educação / Câmara de Educação Superior. Sobre oferta e equivalência de disciplinas à distância no ensino presencial. Ministério da Educação.

CNE/CES (2016) Resolução ${ }^{\circ}$ 5/2016. Institui as Diretrizes Curriculares Nacionais para os cursos de graduação em Computação. Conselho Nacional de Educação / Câmara de Educação Superior. Ministério da Educação. Processo 23001.000026/2012-95. Parecer CNE/CES número 136/2012. Homologação em Diário Oficial em 27 de outubro de 2016.

CNE/CP (2015) Resolução $n^{\circ}$ 2, de $1^{\circ}$ de julho de 2015, que define Diretrizes Curriculares Nacionais para a formação inicial em nível superior (cursos de licenciatura, cursos de formação pedagógica para graduados e cursos de segunda licenciatura) e para a formação continuada. Conselho Nacional de Educação / Conselho Pleno. Ministério da Educação.

CSTA/ISTE (2011) Computational Thinking Teacher Resources, $2^{\text {nd }}$ edition. Computer Science Teachers Association \& International Society for Technology in Education.

INEP (2014) Censo da Educação Superior. Disponível em: http://portal.inep.gov.br/web/censo-da-educacao-superior/censo-da-educacaosuperior.

SBC (2002) CR-LC: Currículo de Referência para Cursos de Licenciatura em Computação. Versão homologada em assembleia da Sociedade Brasileira de Computação em julho de 2002 no Congresso da SBC, Florianópolis - SC.

SBC (2016) Educação Superior em Computação Estatísticas - 2014. Disponível em: http://www.sbc.org.br/documentos-da-sbc/category/133-estatisticas.

SBC (2017) Referenciais de Formação para os Cursos de Graduação em Computação. Comissão de Educação da SBC. Zorzo, A. et al. (Eds.). Disponível em: http://www.sbc.org.br/documentos-da-sbc/summary/127-educacao/1155-referenciaisde-formacao-para-cursos-de-graduacao-em-computacao-outubro-2017

Vasconcelos, V.; Andrade, E. (2018) Análise da Evasão de Alunos na Licenciatura em Computação. Anais do Workshop sobre Educação em Computação - WEI, Natal RN.

Wing, J. (2006) Computational Thinking. Communications of the ACM, Volume 49 Issue 3, March 2006, Pages 33-35. ACM New York, NY, USA.

Wing, J. (2016) Computational thinking, 10 years later. Microsoft Research Blog, March 23, 2016. Disponível em: https://www.microsoft.com/enus/research/blog/computational- thinking-10-years-later/. 